\title{
Biobank sustainability: current status and future prospects
}

\author{
This article was published in the following Dove Press journal: \\ Journal of Biorepository Science for Applied Medicine \\ 9 January 2017 \\ Number of times this article has been viewed
}

\section{Marika Doucet' \\ Martin Yuille ${ }^{2}$ \\ Luke Georghiou ${ }^{3}$ \\ Georges Dagher'}

'Biobanques, Hôpital de la Pitié Salpêtrière, Paris, France; ${ }^{2}$ Centre for Integrated Genomic Medical Research, Division of Population Health, Health Services Research and Primary Care, University of Manchester, ${ }^{3}$ Manchester Institute of Innovation Research, Manchester Business School,

Manchester, UK
Correspondence: Georges Dagher Biobanques, Inserm USI3, Hôpital de la Pitié Salpêtrière, 47, Boulevard de I'Hôpital, Paris 7565I Cedex I3, France $\mathrm{Tel}+33$ | 4216256 |

Email georges.dagher@inserm.fr
Abstract: Biobanks play an important role in biomedical research that aims to understand cellular and molecular mechanisms underlying the development of diseases, and to improve interventions for human health. Despite financial support from mixed public funding streams, long-term sustainability of public biobanks remains a major concern. Review of the literature demonstrates that total cost-recovery strategies, as well as commercialization of research results or derived products, may not represent the best way to reach and maintain sustainability. Public biobanks require support by long-term investment and commitment from public and governmental sources, as well as support from industrial users. In this regard, this study suggests strategies to improve long-term sustainability, such as sample-sharing and biobank consolidation to reduce unit costs, embedding public biobanks in health care systems, and working to implement global funding mechanisms.

Keywords: health, research infrastructure, mixed-model funding, cost recovery, finance

\section{Introduction}

Biobanks are viewed as a research platform that is essential for support of biomedical research that seeks to improve interventions for health and against disease and to understand, for example, the complex relationship between genes and the environment in the development of disease. Despite substantial support from public funding bodies for biobanks and the development of multinational research infrastructures, concerns remain about their long-term financial sustainability. ${ }^{1}$

Interest in this question of sustainability has increased over the last few years, as illustrated by a number of papers published in, for example, the journal Biopreservation and Biobanking. The aims of this article are to review the current state of the sustainability of health-related biobanks and the means whereby they can achieve sustainability for the long term.

\section{Materials and methods Typology of biobanks}

The typology used for the description of biobanks was previously described in the UK Strategic Tissue Repository Alliances Through Unified Methods (STRATUM) project report, and contains five classification categories: purpose, location, and ownership; size, scale, and scope; nature of contents; financing arrangements; and access arrangements. ${ }^{2,3}$ For this review article, two new categories were added, namely cost recovery (access fees) and fees for services. Data were collected 
through a literature review and a questionnaire part of the Pan-European Biobanking and BioMolecular Resources Infrastructure (BBMRI) preparatory phase sent to biobanks in France and the Netherlands.

\section{Literature review}

A literature search was carried out using PubMed in JuneJuly 2016 with the following keywords: biobank(ing) and sustainability, biobank(ing) and business plan, biobank(ing) and financial report. Biobanks were also identified using the references listed in the articles retrieved from PubMed and from the case series of the STRATUM project. Descriptions of biobanks published in the "Biobank profiles" section of the journal Biopreservation and Biobanking were also included, when relevant.

A total of 55 articles related to biobank sustainability were selected from eight journals and one report (Table 1). They described the financial activities of a total of 53 biobanks and eleven networks of biobanks. The biobanks that were investigated in this study originated from the EU (37\%), North America (33\%), Asia (14\%), Australia (11\%), Brazil (3\%), and Russia (2\%). Most of these biobanks were disease-focused (83\%) and mainly supported cancer research. The majority were embedded in public institutions, such as hospitals (41\%) and universities (30\%), whereas 6\% were private companies (Tables 2-4 and Supplementary material). Some biobanks were excluded from our analysis, in particular when the information provided was limited or when they belonged to a larger network. In the latter case, the network was included in our analysis. To ensure that the latest information available was used in this review, biobank websites were identified where possible and information retrieved.

\section{Questionnaire}

A questionnaire was sent by the French infrastructure for biobanks (BB-0033-00001) to public biobanks located in

Table I Journals in which articles and reports on biobank sustainability have been published

\begin{tabular}{lll}
\hline Journal name & $\mathbf{n}$ & $\%$ \\
\hline Biopreservation and Biobanking & 47 & 85 \\
Acta Médica Portuguesa & $\mathrm{I}$ & 15 \\
Alcohol & $\mathrm{I}$ & \\
BMC Medical Ethics & $\mathrm{I}$ & \\
Bundesgesundheitsblatt, & $\mathrm{I}$ & \\
Gesundheitsforschung, Gesundheitsschutz & & \\
Clinical and Translational Science & $\mathrm{I}$ & \\
Clinical Biochemistry & $\mathrm{I}$ & \\
Pathobiology & $\mathrm{I}$ & \\
STRATUM Report & $\mathrm{I}$ & \\
\hline
\end{tabular}

Table 2 Origin of biobanks

\begin{tabular}{lll}
\hline Region or state & $\mathbf{n}$ & $\%$ \\
\hline EU & 24 & 37 \\
North America & 21 & 33 \\
Asia & 9 & 14 \\
Australia & 7 & 11 \\
Brazil & 2 & 3 \\
Russia & 1 & 2 \\
\hline
\end{tabular}

Table 3 Location of biobanks

\begin{tabular}{lll}
\hline Institutional entity & $\mathbf{n}$ & $\%$ \\
\hline Hospital & 26 & 41 \\
University & 19 & 30 \\
Research institute & 4 & 6 \\
Corporate entity & 4 & 6 \\
NA (network) & 11 & 17 \\
\hline
\end{tabular}

Abbreviation: NA, not applicable.

Table 4 Scope and networks of biobanks

\begin{tabular}{lll}
\hline Category of biobank & $\mathbf{n}$ & $\%$ \\
\hline Disease-focused & 53 & 82.8 \\
Population-based & 5 & 7.8 \\
Mixed (disease-focused and & 5 & 7.8 \\
$\begin{array}{l}\text { population-based) } \\
\text { Other }\end{array}$ & $\mathrm{I}$ & \\
\hline
\end{tabular}

France and the Netherlands. The information received was verified for $20 \%$ of these centers by contacting the biobanks. A total of 23 centers from France and 22 from the Netherlands were included in this study (see Supplementary material). In addition to information relating to their typology, biobanks were asked to provide data on operational costs and funding streams.

\section{Results}

Biobanks are highly heterogeneous organizations. ${ }^{4-6}$ When comparing our data to a survey carried out in the US in 2012, however, we found a similarly large proportion of biobanks focusing on cancer research, as well as comparable percentages of public organizations and biobanks included in larger networks. $^{4}$

\section{Operational costs}

Results from the survey of 45 biobanks in France and the Netherlands showed that the annual operational costs of a biobank ranged from $€ 200,000$ (US\$220,000) to $€ 800,000$ (\$880,000), with an average of $€ 400,000$ (\$440,000) per annum. This excluded any expenses related to research. Figures with similar ranges had previously been reported. ${ }^{7}$

The distribution of costs per category is shown in Figure 1. Human resources accounted for $\sim 39 \%$ of the costs, followed 


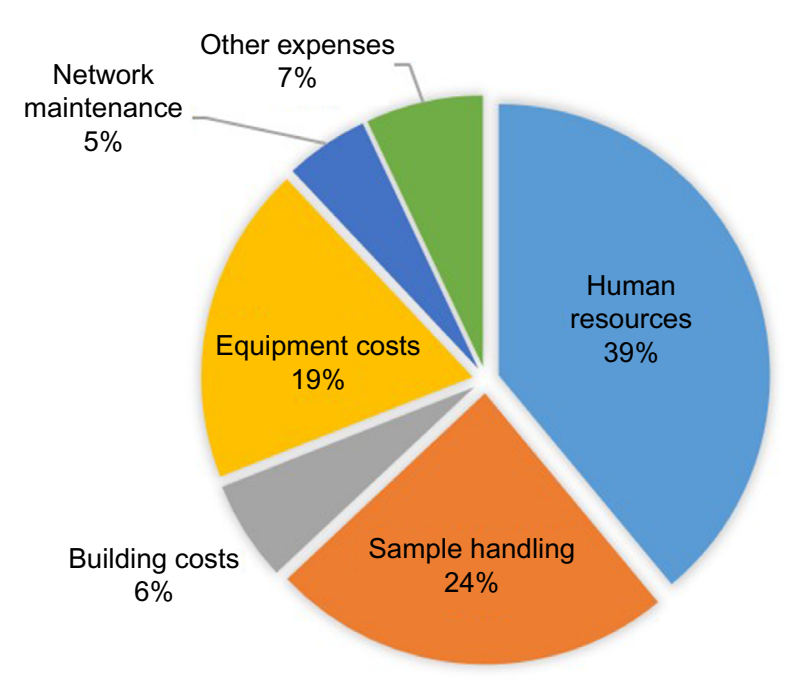

Figure I Annual expenditure for medical research biobanks.

Notes: Building costs, rent, and loans for facilities; equipment costs, IT equipment, depreciation allowance, maintenance contracts for IT, security devices, robots, freezers, nitrogen tanks; human resources, salaries of personnel implicated in biobanking activities (collection, preparation, and storage of biological material), research, and IT (personnel included researchers/MDs, engineers/technicians, quality managers, and administrative staff); network maintenance, costs of maintaining links between biobanks belonging to a specific network (eg, regional, disease-oriented); sample handling, costs for chemical supplies and laboratory consumables necessary for sample handling and preparation of cell derivatives; other expenses, costs for office-related expenses and transportation of biological resources. For all categories described in this figure, amounts in euros were provided by the surveyed biobanks, and percentages of total costs were calculated.

by costs for sample handling and processing (24\%) and capital investment (17\%). Data on costs collected by the Beaumont Health System BioBank and the Biobank Economic Modeling Tool survey reported similar trends, with salaries representing the major expenditure item for biobanks. ${ }^{8,9}$

\section{Funding}

Results from the questionnaire of biobanks in France and the Netherlands revealed that three funding streams of comparable size contribute to their budget: public funding (32\%), funding by research institutions (27\%), and funding by research grants (25\%) (Figure 2). Cost recovery for biological samples contributed just $1 \%$ of the budget. Similar trends with mixed funding streams and limited revenues from user fees were reported in biobanks reviewed in this paper (Supplementary material).

\section{Discussion}

Long-term financial sustainability is a major concern for biobanks. When asked about some of the major challenges faced by their biobanks, many researchers and managers cited financial support as a major hurdle for ensuring the long-term viability of their biobanks. ${ }^{4,9-17}$ Several streams

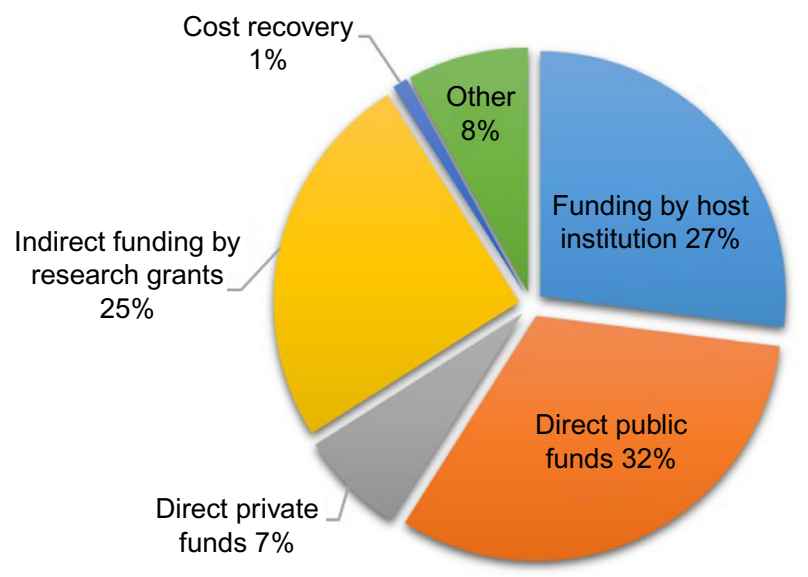

Figure 2 Sources of income for medical research biobanks.

Notes: Cost recovery, income from access fees and services; direct public funds, funding provided by government departments; direct private funds, funding from private partners, such as biotechnology and pharmaceutical companies; indirect funding by research grants, research grants where some funding is dedicated to biobank activities, such as collection of biological resources and preparation of samples. For all categories described in this figure, amounts in euros were provided by the surveyed biobanks, and percentages of total income were calculated.

may contribute to the funding of biobanks: 1) cost recovery related to access to samples, 2) commercialization of research results or derived products, 3) funding from private for-profit entities, such as biotech companies or pharmaceutical corporations, and 4) funding through governmental institutions and agencies.

\section{Cost-recovery strategies related to sample handling and access}

Most of the biobanks analyzed in this review asked users to cover sample handling and shipping; however, it is selfevident that long-term financial sustainability requires more than just covering these marginal costs. ${ }^{18}$ One main reason is that fees charged by biobanks do not cover the real marginal costs for handling samples, let alone the average costs needed to maintain supply. A report commissioned by the Nottingham Health Science Biobank demonstrated that actual costs associated with biobanking were significantly higher than recognized by most researchers and funding bodies, with an average sample costing five to ten times more than estimated by the UK Medical Research Council. ${ }^{19}$ Furthermore, in a study published in 2014, Clément et al assessed the real costs of operational processes in 20 European and US biobanks handling either human samples or microorganisms implicated in human health and disease. ${ }^{20}$ The estimated real costs substantially exceeded the fees charged by the biobank. For example, real costs for a tumor approximated $€ 1,500(\$ 1,680)$, while those for DNA extracted from blood were estimated at $€ 460$ (\$515). While 
only an aliquot or section of a sample may be requested by a user, the probability of that same sample being requested again in the same financial period is probably very low. Therefore, total cost recovery cannot reliably allow for such repeat requests, and would require recovery of all annual costs of accrual, processing, storage, handling, transaction, and depreciation. The fact that the real total costs of accruing, processing, and managing samples is high means that if a biobank seeks to implement a policy to recoup all those costs by charging users, it is highly unlikely to be successful and user resistance is likely. ${ }^{5,21-24}$

Because research based on biobanking is expected to lead directly to improvements in disease prevention and treatment, funding bodies have invested substantial funding in prospective cohorts and clinical studies. These include large population-based prospective cohorts with over 200,000 participants, as well as smaller retrospective disease-research studies. Well-known large studies include the UK Biobank study (500,000 participants), the Kadoorie study of chronic diseases (500,000), EPIC (520,000), LifeGene $(500,000)$, CPTP $(300,000)$, and Constances $(200,000) .{ }^{25}$ Because biobank-based studies serve to increase the well-being of future generations by facilitating innovation in treatment and prevention, any reduction in the scope, number, size, or duration of such studies that followed from a policy of imposing full cost recovery would have negative social and economic impacts.

One cost-reduction strategy for biobanks is to avoid redundancy by sharing samples and associated data and to reduce health care costs, especially in the context of personalized medicine. Biomarkers are currently used to predict survival of patients, assess drug safety, evaluate the immediate consequence on biological processes, identify patients who are more likely to benefit from a treatment, predict outcome given the response to therapy, and monitor disease progression or therapeutic efficacy. ${ }^{26}$ By reducing administration of treatments that do not provide benefit to patients, personalized medicine is likely to contribute to the reduction of health care costs. Implementation of these biomarkers in the clinic however relies on the prior use of a large number of biological samples and associated clinical data from biobanks during their discovery and validation phases. An appropriate quality of samples is a major requirement to achieve this aim. It has been reported that about $30 \%$ of unreproducible results are related to an inappropriate quality of samples and products, which is responsible for $\sim € 9$ billion
( $\$ 8$ billion) per year of unnecessary expenditure in the US alone. ${ }^{27} \mathrm{~A}$ funded national/international strategy aiming to deliver robust diagnosis and reproducible results by the use of an appropriate quality of samples would prove more economically efficient than a cost-recovery strategy aiming to sustain a biobank.

\section{Commercialization of research results or derived products}

The question of whether publicly funded biobanks should claim any ownership of intellectual property rights that are developed by third parties as a result of their access to biobank data and samples has been a topic of debate in recent years. ${ }^{28-31}$ Aside from the legal and theoretical aspects of this question, claiming intellectual property rights requires that the biobank is not only a supplier of biological resources but also participates in downstream research and development activity. In addition, despite their ability to generate returns, patents do not necessarily generate predictable revenues, with both the precise moment and amount of returns difficult to anticipate. As a consequence, it may be challenging to rely on them as a source of stable income that supports the long-term sustainability of a biobank. ${ }^{30}$

\section{Funding from private entities}

Funding from private for-profit entities has raised several ethical and societal issues. ${ }^{1,32,33}$ Several studies and surveys have demonstrated that public trust diminished markedly if industry had funded research projects in public institutes. Reasons cited by individuals included fear over samples or data being used in ways they find morally problematic, loss of control over samples/genetic data and parties they are shared with, limited access to health benefits derived from private or proprietary research, and the extent to which this research was being done for the public good. ${ }^{33,34}$ Therefore, the involvement of commercial entities in public biobanking activities may affect patients' willingness to take part in and consent to research and the degree of public trust, as well as create conflicts of interest that then negatively affect the financial sustainability of biobanks.

\section{Funding from governmental institutions and agencies}

As shown in our survey and reported in Supplementary material, biobanking is currently not capable of covering costs through charges at the point of use, and thus needs to 
be subsidized with governmental and institutional funds. ${ }^{5,35}$ The broad case rests on the widely accepted rationale for government funding of biomedical research, and need not be repeated here. If the majority of use comes from the public sector, then the practical issue lies in identifying the most effective means of allocating the resource, firstly to biobanking as a whole and secondly to users of biobanks.

Allocation of public resources within biomedical research is not a true market, and hence any perceived underfunding of biobanking lies in the failures of the funding system to allocate resources effectively, rather than in the costing system. This failure is most likely to reside in the structure of project-based funding systems, in which biobanking is always a subsidiary input to a proposal. There have been several arguments in the field of research equipment showing how in the absence of complementary institutional funding, generic infrastructure (defined as that not justified by a single project) can be the victim of "hollowing out."36

Assuming the need for subsidy, there are several possibilities for its delivery. One would be to create a quasimarket by encouraging grant holders to budget properly for acquisition of samples and for a fee-based system to be put in place. There are several arguments against this, including the likely high transaction costs and the difficulty of effecting a transition to this model when multiple funders operate in a system. At the other end of the spectrum is complete subsidy: a consortium of public funders meeting all costs and allocating services by means of a peer-review process. This is analogous, for example, to the allocation of beam time at a synchrotron. The issues here would include selection of which biobanks should benefit from subsidy, the nature of contract to be awarded to the biobank, and how efficient the allocation process would be for small-to-medium-sized biobanks. The analogous physical science infrastructures operate on a large scale; indeed, that is their raison d'être.

Ensuring a balance between supply and demand could also be a challenge. On the one hand, if seen as a "free good," samples may be overused, while on the other hand, biobanks may find it difficult to predict what capacity and capabilities they should have to meet demand. There is also a risk that inefficient structures would persist without an incentive to consolidate and scale up. Greater efficiency due to consolidation and scaling up can not only reduce unit costs but may also accelerate the development of biobanking from its beginnings in research to its applications in improved health care. These considerations underlie the UK's NIHR National Biosample Centre initiative, which will test whether this particular approach is sufficiently flexible to deal with the fast-changing and fragmented landscape of health research and public involvement.

A mixed model would appear to be the best compromise, but departing from the present situation by ensuring that core costs are fully covered by relevant funders. Commercial rates (ie, full costs plus a contribution toward sustaining the infrastructure) could and should be applied to commercial users, and indeed would violate EU state-aid provisions if they were not. ${ }^{37}$

Provision of existing subsidies can vary markedly, depending on issues faced by funding bodies and the difficulty in securing highly competitive research grants. ${ }^{8,38}$ Cuts in research-program budgets or reorganization of health care systems following economic policies and crises can additionally endanger the sustainability of biobanks. ${ }^{38}$ In this respect, science generally has been experiencing a shift from Mertonian functionalism to agency-based frameworks that focus on performative processes. This has occurred during a phase when political ideologies shifted from social corporate liberalism to neoliberalism. ${ }^{39}$ In other words, it was argued that the biobanking community must accept market-driven priorities, such as profit, patents/ licenses, sustainability, and the favoring of translational research, aiming to bring products and therapies quickly to market. ${ }^{31,33}$

Biobanks, however, can hardly fit this scheme, because they do not generate profits. They will thus not become sustainable without public support or self-sustaining without acquiring new roles. One such new role is their becoming embedded in health care systems that use longitudinal samples from individuals as part of their personal care. ${ }^{40}$ The BBMRI-ERIC Work Plan has identified this role, recognizing biobanking as not only supporting basic biomedical research but also acting as a service infrastructure. ${ }^{41}$ This opens up new potential lines of support, but also brings into the frame the particular means of costing, pricing, and charging within different health care systems. It might be particularly problematic in systems where a patient moves between providers (whether by choice or by virtue of relocation) and where those providers do not have common access arrangements to historical samples and associated data. Similar arrangements to those being contemplated for health data need to be considered in these circumstances to ensure portability and compatibility while preserving privacy and respecting consent. Another new approach to biobanking sustainability has arisen in the context of 
establishing a global approach to the problem of antimicrobial resistance (AMR). Here, a global funding mechanism has been proposed. ${ }^{42}$ The research required to tackle AMR requires global biobanking with global standards, and this infrastructure will be required as long as AMR remains a health problem for humans and animals. Health care-cost reductions will thus only be attained if biobanks are supported by long-term investment and commitment from public and governmental funding sources, as well as support from industrial users.

\section{Disclosure}

The authors report no conflicts of interest in this work.

\section{References}

1. Caulfield T, Borry P, Gottweis H. Industry involvement in publicly funded biobanks. Nat Rev Genet. 2014;15(4):220.

2. Gee S, Georghiou L, Oliver R, Yuille M. Financing UK biobanks: rationale for a national biobanking research infrastructure. 2013. Available from: http://www.stratumbiobanking.org/docs/STRATUM $\% 20$ COST\%20MODEL\%20FINAL\%20REPORT\%20MAY\%202013.pdf. Accessed November 1, 2016.

3. Gee S, Oliver R, Corfield J, Georghiou L, Yuille M. Biobank finances: a socio-economic analysis and review. Biopreserv Biobank. 2015;13(6):435-451.

4. Henderson GE, Cadigan RJ, Edwards TP, et al. Characterizing biobank organizations in the U.S.: results from a national survey. Genome Med. 2013;5(1):3.

5. Hirtzlin I, Dubreuil C, Préaubert N, et al. An empirical survey on biobanking of human genetic material and data in six EU countries. Eur J Hum Genet. 2003;11(6):475-488.

6. Vaught J. Biobanking comes of age: the transition to biospecimen science. Annu Rev Pharmacol Toxicol. 2016;56:211-228.

7. Carpenter JE, Clarke CL. Biobanking sustainability: experiences of the Australian Breast Cancer Tissue Bank (ABCTB). Biopreserv Biobank. 2014;12(6):395-401.

8. Wilson GD, D'Angelo K, Pruetz BL, Geddes TJ, Larson DM, Akervall J. The challenge of sustaining a hospital-based biobank and core molecular laboratory: the Beaumont experience. Biopreserv Biobank. 2014;12(5):306-311.

9. Odeh H, Miranda L, Rao A, et al. The Biobank Economic Modeling Tool (BEMT): online financial planning to facilitate biobank sustainability. Biopreserv Biobank. 2015;13(6):421-429.

10. [No authors listed]. A network of bioresource facilities in Japan: the human bioresource consortium technical chapter (Japanese association for human bio-resource research). Biopreserv Biobank. 2013;11(1):57-63.

11. [No authors listed]. The Spanish HIV HGM BioBank (SHIVBB). Biopreserv Biobank. 2013;11(4):253-254.

12. Afonso A, Pereira JP, Dias S. Biobanco-IMM, Lisbon Academic Medical Centre. Biopreserv Biobank. 2014;12(6):433-434.

13. Franková V, Jirsová K, Zima T. The Bank of Biological Material (BBM) of the First Faculty of Medicine of Charles University in Prague, Czech Republic. Biopreserv Biobank. 2015;13(4):299-300.

14. [No authors listed]. Canadian tumour repository network. Biopreserv Biobank. 2010;8(4):181-185.

15. [No authors listed]. The Infectious Diseases BioBank (IDB) at King's College London, United Kingdom. Biopreserv Biobank. 2012;10(3):295-296.
16. Sanner JE, Nomie KJ. The biobank at the University of Texas Health Science Center at Houston. Biopreserv Biobank. 2015;13(3):224-225.

17. Cadigan RJ, Lassiter D, Haldeman K, Conlon I, Reavely E, Henderson GE. Neglected ethical issues in biobank management: results from a U.S. study. Life Sci Soc Policy. 2013;9(1):1.

18. Sargsyan K, Macheiner T, Story P, et al. Sustainability in biobanking: model of Biobank Graz. Biopreserv Biobank. 2015;13(6):410-420.

19. Matharoo-Ball B, Thomson BJ. Nottingham Health Science Biobank: a sustainable bioresource. Biopreserv Biobank. 2014;12(5):312-316.

20. Clément B, Yuille M, Zaltoukal K, et al. Public biobanks: calculation and recovery of costs. Sci Transl Med. 2014;6(261):261fs45.

21. Parry-Jones A. Assessing the financial, operational, and social sustainability of a biobank: the Wales Cancer Bank case study. Biopreserv Biobank. 2014;12(6):381-388.

22. Seiler CY, Eschbacher J, Bowser R, LaBaer J. Sustainability in a hospital-based biobank and university-based DNA biorepository: strategic roadmaps. Biopreserv Biobank. 2015;13(6):401-409.

23. Albert M, Bartlett J, Johnston RN, Schacter B, Watson P. Biobank bootstrapping: Is biobank sustainability possible through cost recovery? Biopreserv Biobank. 2014;12(6):374-380.

24. Galbraith JW. Sustainability in the modern biorepository environment from the perspective of the Tissue Procurement Core at the University of Iowa. Biopreserv Biobank. 2015;13(6):430-432.

25. Imboden M, Probst-Hensch NM. Biobanking across the phenome: at the center of chronic disease research. BMC Public Health. 2013;13:1094.

26. de Gramont A, Watson S, Ellis LM, et al. Pragmatic issues in biomarker evaluation for targeted therapies in cancer. Nat Rev Clin Oncol. 2015;12(4):197-212.

27. Freedman LP, Cockburn IM, Simcoe TS. The economics of reproducibility in preclinical research. PLoS Biol. 2015;13(6):e1002165.

28. Nielsen J. Reach-through rights in biomedical patent licensing: a comparative analysis of their anti-competitive reach. Fed Law Rev. 2004;32(2):169-204.

29. Winickoff DE. Partnership in U.K. Biobank: a third way for genomic property? J Law Med Ethics. 2007;35(3):440-456.

30. Pathmasiri S, Deschênes M, Joly Y, Mrejen T, Hemmings F, Knoppers BM. Intellectual property rights in publicly funded biobanks: Much ado about nothing? Nat Biotechnol. 2011;29(4):319-323.

31. Birch K, Dove ES, Chiappetta M, Gürsoy UK. Biobanks in oral health: promises and implications of post-neoliberal science and innovation. OMICS. 2016;20(1):36-41.

32. Evers K, Forsberg J, Hansson M. Commercialization of biobanks. Biopreserv Biobank. 2012;10(1):45-47.

33. Caulfield T, Burningham S, Joly Y, et al. A review of the key issues associated with the commercialization of biobanks. J Law Biosci. 2014;1(1):94-110.

34. Nicol D, Critchley C, McWhirter R, Whitton T. Understanding public reactions to commercialization of biobanks and use of biobank resources. Soc Sci Med. 2016;162:79-87.

35. Barnes RO, Schacter B, Kodeeswaran S, Watson PH. Funding sources for Canadian biorepositories: the role of user fees and strategies to help fill the gap. Biopreserv Biobank. 2014;12(5):300-305.

36. Georghiou LG, Halfpenny P. Equipping researchers for the future. Nature. 1996;383(6602):663-664.

37. European Union. Consolidated version of the Treaty on the Functioning of the European Union: article 107. 2012. Available from: http://eurlex.europa.eu/legal-content/EN/TXT/?uri=celex\%3A12012E\%2FTXT. Accessed November 1, 2016.

38. Riegman PH. From AAA+ to BB- and on the way back again. Biopreserv Biobank. 2014;12(5):292-293.

39. Hess DJ. Neoliberalism and the history of STS theory. Soc Epistemol. 2013;27(2):177-193.

40. Harris JR, Burton P, Knoppers BM, et al. Toward a roadmap in global biobanking for health. Eur J Hum Genet. 2012;20(11):1105-1111. 
41. Biobanking and BioMolecular Resources Research Infrastructure [website on the Internet]. Available from: http://bbmri-eric.eu. Accessed September 5, 2016.
42. Laxminarayan R, Sridhar D, Blaser M, Wang M, Woolhouse M. Achieving global targets for antimicrobial resistance. Science. 2016;353(6302):874-875
Journal of Biorepository Science for Applied Medicine

\section{Publish your work in this journal}

The Journal of Biorepository Science for Applied Medicine is an international, peerreviewed, open access journal that focuses on new developments and advances in the emerging and evolving field of biorepository science. This includes biospecimen procurement, processing, preservation, and banking for application to applied medicine The Journal invites submission of manuscripts which address these aspects in additio to systems logic, clinical throughput and ethical issues pertaining to application of

Submit your manuscript here: https://www.dovepress.com/journal-of-biorepository-science-for-applied-medicine-journa

\section{Dovepress}

biorepositories and their effects on clinical medicine. The journal is characterized by the rapid reporting of reviews, original research, methodologies, technologies and analytics in this subject area. The manuscript management system is completely online and includes a very quick and fair peer-review system, which is all easy to use. Visit http:// www.dovepress.com/testimonials.php to read real quotes from published authors. 